\title{
Economies of Scale in UK Life Insurance Companies: An Empirical Approach
}

\author{
by Geraldine Kaye*
}

\section{Background to current study}

On the 28th April 1986 a paper entitled "The Life Offices Association's Inter-Office Expense Investigation" (Luffrum, O'Leary and Shedden, 1986) was presented to the Institute of Actuarics at Staple Inn in London. It was later presented to the Faculty of Actuaries in Scotland.

The paper described the Life Offices Association's inter-office cxpense investigation (IOEI) which has been set up so that data on life office costs might be made available to the actuarial profession and their significance discussed. The paper included various expense analyses. One of these analyses used a linear regression equation to determine if economies of scale were being achieved by life insurance offices. (Pages 372 to 374 of the paper). The authors stated that they would have liked to pursue the subject further, but were severely restricted by the problem of confidentiality. The basic data are strictly confidential : without knowledgc of which data rclate to which office, it is impossible, for example to cxclude unsuitable outliers or utilise additional information about the offices etc.

The ABI decided to ask The Department of Actuarial Science and Statistics at City University to undertake the project since it has both the technical expertise and knowledge of the market as well as being able to deal with the problem of confidentiality in a satisfactory way. In October 1986, it was agreed that the present author would undertake a rescarch project into ccononies of scalc.

The question originally posed by the ABI are "Are there any economies of scale within the life insurance industry?". The concept of economies of scale appears easy to understand intuitively and could superficially be translated as "Is the consumer getting more value for moncy from a large or small insurer?". It is intcresting to notc that this question was raised in the general press as early as 1874 by J. R. Macfayden (1874), who concluded that from the consumer's point of view a small company was preferable to a large.

A study of "valuc for money" is more than just a study of cxpense in relation to various measures of output. Expense, whilst a significant constituent of what will form a policyholder's final return still comprises only one of many such constituent parts; many of which such as quality of service are unquantifiable.

\footnotetext{
* Senior Research Fellow, City University, London. England.
} 


\section{How should output be measured?}

Traditional techniques of measuring economies of scale may be inappropriate to the life insurance industry. The main problem arises from the difficulty of finding an appropriate measure of size. Output in terms of the added value to the economy is often used as the measure of size because it best reflects what is available for consumption. This raises the question of whether the nueasure of size should be physical (eg number of policies) or a measure of value (eg money's worth of premiums or assets) or even hypothetical (eg constructed from expected expenses). As it may seem strange to use expcnses of any form as a measure of size/output it is worth stating here an argument for its use: in buying an investment oricntated life policy a person is buying administrative scrvices.

There is evidence that many U.K. life insurance firms follow a "cost plus" pricing policy for premiums i. e. calculate a theoretical premium and then add an allowance for cxpenses (Blunden, 1986). This approach as applied to recurrent single premiums is described in R. H. Ranson and C. P. Headdon (1989: 313).

“... each premium paid, after an explicit deduction... The explicit deduction is designed to ensure that each contract bears a fair share of expenses and also to meet the costs of any other benefits..."

Even those companies which do not follow this approach make assumptions about the level of expected expenses based on their prior knowledge of past expenses and determine notional expense levels known as loadings. These loadings are then used when profit-testing test premiums and in this indirect manner determining structure; therefore, if we measure expenses against premiums a component of what should be the independent variable will in fact be dependent. If this component is sizeable then parameter estimates will be meaningless biased and inconsistent (Johnston, 1960). C. D. O'Brien (1989) also rejects the use of premiums as an output indicator because of their transfer element. Such problems have been dealt wiith at length by N. A. Doherty, (1981). Unfortunately, his methods whilst applicable to general insurance are not readily adaptable to life insurance as his chosen size measure is claims paid. For life insurance claims are often made on surrender or maturity and therefore contain a large "transfer" element." The amount of this element will be highly dependent on the bonus loading in the original premium.

This is best illustrated by a practical example. Take two companies A and B both marketing a with-profit policy with identical costs per policy. Company A has double the bonus loading of company $\mathrm{B}$. It is obvious that using premiums or indeed claims as the sole output mcasure will make company A look more efficient than company B. In simplistic, terms the extra bonus loading charged by company A should have been thought of only as a 'transfer element'. If this 'transfer element' were removed, both companies would appear equally efficient.

The problems of using premium income as an output because of its 'transfer element' have been pointed out by R. R. Gechan and Hirshhorn (1977). Their method is to use an output mcasure which is a weighted average of the costs of various services undertaken such as the issue or renewal of a policy, distinctions being made between various classes of policy.

1 "We take the savings..., we earn what we can... and pay it out" (Ranson and Headon, 1989: $341)$ R. H. Ranson replying to the paper he co-authored. 
Such measures are not readily available for the U.K. industry although the ABI expense investigation could be uscd as a starting point.

In his most recently published paper R. R. Gechan (1986) says "In my opinion the determination of an appropriate measure of output constitutes the single most important problcm for research in this area". R. R. Geehan has approached the subject of measuring size from the macroeconomic viewpoint of national income. The measure of size from the microeconomic/consumer viewpoint is not output, with all its corresponding problems of definition, but premiums or possibly assets. To determine an appropriate measurc of output one must first consider what is the function of a life office. "A life insurance company thus has two general functions: to service the insurance contracts of its policyholders and to manage the savings entrusted to it." (Gechan and Hirshhorn, 1977: 212). This definition of the function of a life office lcads in naturally to the measure of output used by R. R. Geehan. Considering the function of the life office to be the production of the contracts to which he and R. Hirshorn refer leads more naturally to a measure such as premiums. R. R. Geehan's (1977) proposed macrocconomic solution to the problem falls short of the ideal by being too subjective. The elements of subjectivity arise in the choice of standard expense units as used by the Canadian Institute of Actuaries and developed by A. Pedoe (1952 and 1961). R. R. Geehan bases his output measures on these standard expense units. He assumes that they have an objective foundation. He does not seek to question how they are derived. A. Pedoe (1961) discusses various formulae to derive the standard expenses and explains that they are determined by committees rather than scientifically. "That actuarial opinion is vague and varied on this subject is acknowledged." (Pedoe, 1961: 18).

C. D. O'Brien takes in his concluding paragraphs a similar theoretical approach to the measure of output as R. R. Geehan.

"It is possible to view output of a life assurance firm, or of the industry, as being the sum of the factor incomes... This approach emphasises output as being the servicing activities involved," (O'Brien, 1989: 35).

A disadvantage of this approach is that it could credit the most inefficient firm (i.e. highest expenses) as having the highest output.

D. C. Houston and R. M. Simon (1970) use three measures of output based on premiums: namely log premiums, reciprocal of log premiums and reciprocal of premiums. They conclude that "one can be relatively indifferent... as to which of the variables is chosen to demonstrate increasing returns to scale" (p. 861). They did not consider premiums without any transformation. D. W. Colcnutt (1977b) who followed the methodology of D. C. Houston and R. M. Simmon (1970) did consider premiums. "The linear form of the size variable was a poor fit and clcarly unsuitable..." (p. 221). His conclusion was probably reached as a result of using average costs rather than total costs (which is used in this paper) as the dependant variable.

There is controversy as to whether the use of premiums would exaggerate or suppress scalc cconomies. Opposite points of view are taken by two of the leading experts in this field. R. R. Geehan (1977a) suggests that premiums as a measure of output exaggerate scale economies. N. A. Doherty (1981) suggest that premiums as a measure of output suppress scale economies. "Since premium rates appear to be negatively related to firm size the use of a premium based output mcasure might fail to reveal or understate the existence of scale 
economies" (p. 401). There can be little doubt that premium income is not an ideal measure of output but for the present it is the best we have. Advantages of using premiums as the output measure are that comparisons can be made with the work of previous researchers and whilst results cannot be considered definitive they may be indicative of likely results.

This study will be undertaken from the management perspective rather than the consumer's. The measure of output used will be premiums as any results can easily be applied by the insurance industry.

\section{Single equation model}

Most previous studies of cost/size relationships and/or economies of scale have used multiple regression models. Results of multiple regression analyses are often unsatisfactory owing to the inclusion of many variables. These increase the number of statistical assumptions made and the qualifications required before the results can be used (and also the number of grounds on which subsequent researchers can challenge the work and refute the results). A balance must be drawn between including many variables, and excluding them with the consequent danger of reducing a model's potential explanatory power and increasing bias.

A particular problem is the presence of multicollinearit $y^{2}$ between variables which one cannot easily control. Economic variables are often correlated and therefore this problem cannot be solved using straightforward multiple regression techniques. Multicollinearity renders estimates inefficient. Another problem is that some variables are likely to be dimensionless (e.g. type of ownership; mutual/proprietary); and so are given values of either 0 or 1 . This encourages researchers to use ratios for variables instead of absolute values. Ratios, however, are suspect as they combine two variables and may lose explanatory power.

This paper returns to first principles and seeks a simple model-which could apply without the need for ratios. The study looks at the relationship of premiums ${ }^{3}$ to expenses cross-sectionally and also sequentially through time $(1980-1986)$ as the trend of the parameters is important. The overwhelming advantage of premiums as a measure of output is that conclusions relating to it will have direct relevance to insurance management ${ }^{4} \mathrm{~A}$ single-equation model is tested using the pane ${ }^{5}$ data (repeated surveys of a single cross-section sample in different periods of time) provided by the ABI.

2 The term multicollincarity is used to denote the presence of linear relationships (or ncar lincar relationships) among explanatory variables. Intuitively, when any two explanatory variables are changing in nearly the same way, it becomes extremely difficult to establish the influence of each one regressor on $\mathrm{Y}$ separately. In this study an example would be whether a company is industrial or not and the type of sales force it uses.

${ }^{3}$ Premiums can certainly be considered as a proxy for size even if there is controversy over whether they are an adequate representation of output. This controversy is discussed in R. R. Geehan (1977) and developed by C. D. O'Brien (1989).

${ }^{4}$ Many of the other measures of output have been derived by economists for use, eg in computing official Government statistics, and only have direct relevance at the aggregate level of the national economy.

5 To ease comparisons over time only those companies contributing to the ABI survey in every year 1980-1986 are included. There are 43 such companics. 
The use of a single equation model sacrifices, to a certain extent, the accuracy of estimates in order to facilitate their estimation. Equations are formulated in section 4 for each year separately (Table 1).

The ABI data is in a sense fortuitous. That is to say it was collected for purposes other than the statistical investigation for which it is now being used. It is not, therefore, the result of any carefully designed and executed experiment. As the sample consists of companies who have voluntarily submitted expense data on a regular basis for at least seven years, it is likely that their systems for expense control are better than for the industry in general. It is also likely that ABI companies have lower expenses than the industry in general. ${ }^{6}$

The behavioural relationship between expenses and premiums must be simplified by abstracting a functional relationship between the variables. To do so, simple scatter plots of the variables jointly were used. (Pictures are often a useful guide to the comprehension of fundamentals). A logarithmic transformation of both sets of variables ${ }^{7}$ was made.

A log-log transformation did in fact produce a better fit. The transformation asserts an underlying curve of the form

$$
Y=B_{0} X^{B_{l}}
$$

\section{Table 1}

\begin{tabular}{|c|c|c|c|c|}
\hline YEAR & $\begin{array}{l}\text { REGRESSION EQUATION } \\
4 ! \text { degrees of freedom }\end{array}$ & $\begin{array}{l}\text { COEFF. OF } \\
\text { DETERM. } \%\end{array}$ & $d^{48}$ & $r^{9}$ \\
\hline 1980 & $\mathrm{Y}=\frac{1.25}{.68}+0.868 \mathrm{X}+\mathrm{e}$ & 92.2 & 1.96 & $\begin{array}{l}\mathrm{r}-.11 \\
\mathrm{t} \\
\mathrm{t}\end{array}$ \\
\hline 1981 & $\mathrm{Y}=\frac{1.33+0.864 \mathrm{X}+\mathrm{e}}{.73 \quad .060}$ & 91.2 & 2.13 & $\begin{array}{l}r-.10 \\
t \quad .65\end{array}$ \\
\hline 1982 & $\mathrm{Y}=\frac{1.13}{.75}+0.856 \mathrm{X}+\mathrm{e}$ & 91.0 & 2.08 & $\begin{array}{l}\mathrm{r}-.07 \\
\mathrm{t} \quad .65\end{array}$ \\
\hline 1983 & $\mathrm{Y}=\frac{0.61}{.78}+0.900 \mathrm{X}+\mathrm{e}$ & 91.3 & 2.28 & $\begin{array}{l}r-.18 \\
t \quad 1.15\end{array}$ \\
\hline 1984 & $\mathrm{Y}=\begin{array}{c}0.50 \\
.80\end{array}+\frac{0.893 \mathrm{X}+\mathrm{e}}{.043}$ & 91.1 & 2.48 & $\begin{array}{l}r-.26 \\
t \quad 1.70\end{array}$ \\
\hline 1985 & $\mathrm{Y}=0.71+0.881 \mathrm{X}+\mathrm{e}$ & 90.9 & 2.14 & $\begin{array}{l}r-.19 \\
\mathrm{t} \quad 1.20\end{array}$ \\
\hline 1986 & $\mathrm{Y}=\begin{array}{c}0.50 \\
.82\end{array}+0.890 \mathrm{X}+\mathrm{e}$ & 91.0 & 2.00 & $\begin{array}{l}\mathrm{r}-.03 \\
\mathrm{t} \\
\mathrm{t}\end{array}$ \\
\hline
\end{tabular}

Where $\mathrm{Y}$ is $\log _{\mathrm{c}}$ (expenses) and $\mathrm{X}$ is $\log _{\mathrm{c}}$ (premiums)

\footnotetext{
6 A study based on 1981 expenses was included in J. Tapp (1986), this demonstrated that ABI companies had lower expenses than non-ABI companies.

7 This if often referred to as a log-log transformation.

${ }^{8}$ Refer to para 2.2 .

9 To test for heteroscedasticity Spearman's rank correlation test was applied to the residuals. Student's $t$ test was then applied to test for their significance.
} 
This is convenient as it implies that if economies of scale are present then they are constant and equal $B_{l}$. The transformation is not appropriate for 'long stretches' of curve, but is useful for the light it throws on the nature of rclationships. (Livcscy, 1983).

\subsection{Parameter estimates}

For ease of reference, the standard error of each of the rcgression parameters estimated $\hat{B}_{l}(i=0, I)$ is shown directly below the corresponding parameter estimate.

Formally, we will test the hypothesis $H_{0}: B_{I}=0$ against the

alternative $\quad H_{l}: B_{l} \neq 0$.

We use a two tail test at the $5 \%$ level of significance. Wc accept that the parameter $B$ is different from 0 if the standard error of the estimate is less than half its numerical value. (Thc use of $1 / 2$ is a rough approximation to $1 / 1.96=$ where 1.96 is the usual $95 \%$ critical value). A two tailed test is used for consistency, because although expenses cannot fall as premiums increase, it may be possible for them to fall as other variables which could be considered later are increased. If, on the other hand, the null hypothesis is accepted, we conclude that the least squares estimate is not significantly different from zero.

It can easily be seen from Table 1 that all the estimates of the $B_{i}$ 's are significantly different from zero. The values returned by the test are so extreme that it will serve no purpose at this stage to introducc a morc sophisticatcd test to fine-tunc the results.

Trends in $B_{0}$ and $B_{l}$ appear to be present. It is important, therefore, that caution is used in generalising the conclusions reached in those published works on economies of scale where the authors have uscd only onc ycar's data: for example, Gechan (1977) and Practz (1983).

Estimation of $B_{\theta}$ depends on the units chosen to measure $X$ and $Y$ and $B_{0}$ can be thought of as a scaling factor. Although changing the scale of measurement of $X$ and $Y$ will change the absolute value of $B_{0}$ the form of the original relationship i. c. $\log Y=\log B_{0}+$ $B_{l} \log X$ and the value of $B_{l}^{10}$ remain constant.

In Table 1 it is interesting that the trend of the $B_{0}$ 's reduces over time. This may to a large extent be explained by the effects of inflation and other factors tending to increase both the level of premiums and expenses.

The pattern of the $B$ is over time is also intercsting. 1982 marked the end of a practically industrywide commissions agreement. In 1983, Miras (Mortgage interest rclief at sourcc) was introduced causing a boom in sales of endowment policies. This shows through in $B$, for 1984 being lower than for 1983. In the 1984 Budget, it was announced that LAPR (Life assurance premium relief) was to be removed. In the few weeks prior to its removal, another surge in sales took place. This may seen perverse but the industry used as its sales ploy "buy now before its too late". 1985 saw a similar boom this time for pensions business. The threat to remove tax relicf ncver materialised but in the UK there is no cash return to

${ }^{10}$ Consider what happens if both $X$ and $Y$ are scaled by a factor $K$ ie $Y^{I}=K Y$ and $X^{l}=K X$ then $\log Y^{\prime}=\log B_{0}-\left(I-B_{I}\right) \log K+B_{l} \log X^{\prime}=\log B_{0}^{\prime}+B_{l} \log X^{\prime}$.

$B_{0}$ changes to $B_{\theta}^{\prime}$ but $B_{l}$ remains unchanged, where $\log B_{\theta}^{\prime}=\left(1-B_{l}\right) \log K$ if $B_{1}<1$ and $K>I$ then $B_{0}^{\prime}$ $<B_{0}$. 
the client if a pension plan is lapsed and so sales made could not be reversed. 1986 saw the advent of the Financial Services Act. Its dramatic effects would be shown by the analysis of 1987 and later data which has not been made available.

\subsection{Autocorrelation}

At the $5 \%$ level of significance, the Durbin Watson ${ }^{11}$ test proves to be inconclusive in only 1984 and only in respect of negative auto correlation. So, for 1984 , strictly speaking inferences cannot be madc; however, the test statistic is so close to the bordcrline for that year that, for this kind of preliminary investigation, we are content to assume that no autocorrelation either positive or negative exists in any year.

\subsection{Heteroscedasticity}

As the calculated $t$ statistics shown in Table 1 (immediately below the corresponding Spearman's correlation coefficient) are not significant at the $5 \%$ level, the null hypothesis of homoscedasticity holds and it is concluded that there is no heteroscedasticity for any of the years considered.

\section{Size breaks}

To determine if economies of scale exist, the curve must now be split into size bands and the corresponding curves tested to decide if structural differcnces exist between them. If the structure does differ between sections of the curve, the corresponding coefficients are likely to be different, and the cocfficients cstimatcd from the unificd sample will not bc reliable.

Each year, the ABI (LOA as it was) categories into size bands those companies which contribute datas to its "expensc survcy". 1981 is the first year for which these sizes are still readily available.

Introducing dummy indicator variables for size is onc method of detecting whether structural differences cxist (Dutta, 1975: 177). So the following are introduced to represent size categories:
Small
Mcdium
Large
size $1=1$
size $2=0$
size $3=0$
$\operatorname{sizc} 1=0$
$\operatorname{sizc} 2=1$
$\operatorname{sizc} 3=0$
size $1=0$
size $2=0$
size $3=1$

and further dummy variables are introduced to test the slope:

$$
\begin{aligned}
& \text { Slope } 1=\log (\text { premiums }) \times \text { size } 1 . \\
& \text { Slope } 2=\log (\text { premiums }) \times \text { size } 2 . \\
& \text { Slope } 3=\log (\text { premiums }) \times \text { size } 3 .
\end{aligned}
$$

The independent variables which will be used are $\log$ (premiums), size 2 , size 3 , Slope 2 and Slope 3.12 The dummy variables for small size category are not entered into the equation

11 "The econometrician feels comfortable when his computed $d$ is close to 2." (Dutta, 1975: 113).

12 Including irrelevant variables increases the standard errors of all estimates without improving prediction. The method used to calculate this regression equation enters each variable in turn and calculates whether its presence improves the predictive ability of the model (as defined by $R^{2}$ ). In this manner "irrelevant variables" are determined and omitted. It should be noted that if variables are highly correlated this method can produce different regression equations according to the order in which variables are entered. 
as they are superflouos. ${ }^{13}$ Including all three size variables and a constant term is an example of 'the dummy variable trap', since a linear combination can be formed which is collinear with the constant term.

\subsection{1}

\subsection{Original ABI sizebreaks}

In the 1981 report of the Productivity (Expenses) Panel of the ABI small companies are those with premium income $£ 40,000,000$ or less: medium are those producing over $£ 40,000,000$, but less than $£ 130,000,000$ : large are those producing $£ 130,000,000$ or more. ${ }^{14}$

The ratio of total expenses including commission to revenue premiums was calculated for each size band:

\begin{tabular}{lccc} 
& \multicolumn{3}{c}{ Table 2 } \\
& Mean of ratio & SD & No. of cases \\
Small & 31.77 & 7.85 & 11 \\
Medium & 23.17 & 6.95 & 21 \\
Large & 19.52 & 5.50 & 11 \\
\hline All & 24.43 & 8.13 & 43
\end{tabular}

Regression Equation

$\log ($ expenses $)=.03+.93 \log ($ premiums $)-.01$ Slope $2-.02$ Slope 3.

Regression Equation Statistics

$\begin{array}{lcccl}\text { Variables } & \mathrm{B} & \mathrm{SF}(\mathrm{B}) & \mathrm{t} & \text { Sig } \mathrm{t}^{15} \\ \text { Slope } 3 & -.02 & .02 & -1.05 & .30 \\ \text { Slope } 2 & -.01 & .01 & -1.11 & .27 \\ \log \text { (premiums) } & .93 & .09 & 10.67 & .00 \\ \text { constant } & .03 & 1.42 & .02 & .98\end{array}$

Adjusted $\mathrm{R}^{2}=.91^{1 \mathrm{k}} \quad \mathrm{DW}=2.04$

It is concluded in this case that there are no structural differences between the "three lines" as the slope coefficients for the "medium" and "large" sections of the line are not significantly different from zero.

\subsubsection{Revised ABI sizebreaks}

All references to 1981 in later years' reports of the Productivity (Expenses) Panel of the ABI refer to $£ 75 \mathrm{~m}$ as the boundary of small to medium companies rather than the $£ 40 \mathrm{~m}$ referred to in the 1981 report. The above analysis was therefore repeated using the revised size band.

\footnotetext{
${ }_{13}$ Consider the more simple case where the data is split into only two categories: small and large. If large does not feature as significant then there is no significant break. If large does then there is. This is all one requires to know at this stage when considering structural breaks.

14 "The groupings by size were determined so that about half the offices fell into the medium group and the remainder were split more or less evenly between the large and small groups." (Luffrum, O'Leary \& Shedden, 1986: para 2.4.3.).

15 This is a two tailed test statistic. The significance test shows the probability that this value could occur by chance.

${ }_{16}$ The adjustment made to $\mathrm{R}^{2}$ is designed to correct $\mathrm{R}^{2}$ to more closely reflect the goodness of fit of the model when more than one independent variable is present.
} 
The revised breakdown by number of cases and expense ratios is as follose:

Table 3

\begin{tabular}{lccc} 
& Mean of ratio & SD & No. of cases \\
Small & 29.58 & 7.33 & 21 \\
Medium & 19.53 & 5.63 & 11 \\
Large & 19.52 & 5.50 & 11 \\
\hline All & 24.43 & 8.13 & 43
\end{tabular}

Regression Equation

$\log$ (expenses) $=-.51+.96 \log ($ premiums $)-.02$ Slope $2-.02$ Slope 3.

Regression Equation Statistics

$\begin{array}{lcccc}\text { Variables } & \mathrm{B} & \mathrm{SE}(\mathrm{B}) & \mathrm{t} & \text { Sig t } \\ \text { Slope 3 } & -.02 & .01 & -1.88 & .07 \\ \text { Slope 2 } & -.02 & .01 & -2.64 & .01 \\ \text { log (preniums) } & .96 & .06 & 14.96 & .00 \\ \text { constant } & -.51 & 1.09 & -.47 & .64\end{array}$

Adjusted $\mathrm{R}^{2}=.92 \quad \mathrm{DW}=2.04$

Here there are significant structural differences between the medium and small size bands, since Slope 2 is significant at the $1 \%$ level: with large size having a bearing as Slope 3 is also significant, but only at the $7 \%$ level. This would indicate that economies of scale could exist and that if so their extent increases with the size of the company. The word 'could' has been used deliberately since any such conclusion conflicts with the first analysis which demonstrated no such structural break. For that first analysis the grouping was large (11), medium (21) or small (11). For the revised grouping the number of cases in the large group remains unchanged (11): there are the same number of cases as before in small and medium taken together and yet a large size appears to be associated with structural differences, whereas previously it did not. Too great a significance should not be attributed to this result as the later sizebands were deliberately chosen by the ABI, with hindsight.

\subsection{6}

\subsubsection{AB1 sizebreaks}

By only one main subdivision is made for the ABI data: $\$ 180 \mathrm{~m}$. A further subdivision $£ 620 \mathrm{~m}$ is made for the "expenses only" investigation.

Using both subdivisions as breakpoints the breakdown by number of cases and cxpensc ratios is as follows:

\begin{tabular}{lccc} 
& \multicolumn{3}{c}{ Table 4} \\
Small & Mean of ratio & SD & No. of cases \\
Medium & 24.76 & 7.42 & 20 \\
Large & 21.04 & 1.72 & 5 \\
\hline All & 18.13 & 4.44 & 18 \\
\hline & 21.55 & 6.57 & 43
\end{tabular}

Regression Equation

$\log ($ expenses $)=-1.73+1.02 \log ($ premiums $)-.01$ Slope $2-.02$ Slope 3 . 
Regression Equation Statistics

$\begin{array}{lcccc}\text { Variables } & \mathrm{B} & \mathrm{SE}(\mathrm{B}) & \mathrm{t} & \text { Sig t } \\ \text { Slope 3 } & -.02 & .01 & -1.78 & .08 \\ \text { Slope 2 } & -.01 & .01 & -.79 & .43 \\ \log \text { (premiums) } & 1.02 & .08 & 12.23 & .00 \\ \text { constant } & -1.73 & 1.49 & -1.16 & .25\end{array}$

Adjusted $\mathrm{R}^{2}=.91 \quad \mathrm{DW}=1.95$

Here it looks as if large size may have a bearing on the existence of a structural break between medium and large size companies. It can, however, be seen that there are only 5 cases in the medium size category and yet another sizebreak is tested.

\subsubsection{Adjusted ABI sizebreaks}

A more comparable split with 1981 would use breakpoints $£ 80 \mathrm{~m}$ and $£ 360 \mathrm{~m} \cdot{ }^{17}$

\section{Table 5}

\begin{tabular}{lccc} 
& Mean of ratio & SD & No. of cases \\
Small & 26.02 & 9.14 & 11 \\
Medium & 20.92 & 4.47 & 21 \\
Large & 18.29 & 4.78 & 11 \\
\hline All & 21.55 & 6.56 & 43
\end{tabular}

Regression Equation

$\log$ (expenses) $=-.57+.95 \log$ (premiums) +.01 Slope $3+.01$ Slope 2.

Regression Equation Statistics

$\begin{array}{lrrrl}\text { Variables } & \mathrm{B} & \mathrm{SE}(\mathrm{B}) & \mathrm{t} & \text { Sig t } \\ \text { Slope } 3 & .01 & .01 & -.59 & .56 \\ \text { Slope } 2 & .01 & .01 & .49 & .62 \\ \log \text { (premiums) } & .95 & .10 & 9.43 & .00 \\ \text { constant } & -.57 & 1.91 & -.30 & .77\end{array}$

Adjusted $\mathrm{R}^{2}=.91 \quad \mathrm{DW}=2.37$

Here it easily be seen that there are no significant structural breaks between size bands.

\subsubsection{Sizebreaks comparable to 1980}

For complete comparability of results with 1981 one further analysis will be made using 11 companies in each of the large and medium groups.

Table 6

\begin{tabular}{lccc} 
& Mean of ratio & SD & No. of cases \\
Small & 24.60 & 7.26 & 21 \\
Medium & 18.98 & 3.74 & 11 \\
Large & 18.29 & 4.79 & 11 \\
\hline All & 21.55 & 6.56 & 43
\end{tabular}

${ }^{17}$ Splitting companies into size categories on the basis of proportionate numbers of companies in each group is the method used by the ABI in earlier years. 


\section{Regression Equation}

$\log ($ expenses $)=-1.33+.99 \log ($ premiums $)-.01$ Slope $2-.01$ Slope 3.

Regression Equation Statistics

$\begin{array}{lcccl}\text { Variables } & \mathrm{B} & \mathrm{SE}(\mathrm{B}) & \mathrm{t} & \mathrm{Sig} \mathrm{t} \\ \text { Slope } 3 & -.01 & .01 & -1.35 & .19 \\ \text { Slope } 2 & -.01 & .01 & -1.42 & .16 \\ \text { log (premiums) } & .99 & .08 & 11.89 & .00 \\ \text { constant } & -1.33 & .51 & -.88 & .38\end{array}$

$$
\text { Adjusted } \mathrm{R}^{7}=.91 \quad \mathrm{DW}=2.05
$$

Here again there are no significant structural differences between the three size bands.

\section{Grouping data}

The two analyses for 1981 with differing "break points" and consequently different conclusions confirm the importance of the choice of "break points" in conclusions reached.

A similar point has been raised in the literature where Adelman (1980) claims to show that economies of scale exist where Cummins (1977) found that they did not. The reason for conflicting results is given by Adelman (1980) as due to Cummins study possibly modelling the rate of change of the total cost function over the point where the cost function changes, whereas his own study models over different ranges capturing the "real" rate of change of the total cost function.

Several different criteria have been used for breakpoints in the hope of ascertaining an empirical objective criterion.

The problem is to determine an objective criterion for the break points and at the same time to avoid the "hindsight heresy" of searching the data for results to fit the conclusions one wishes to reach. Very many hours could be devoted to such analysis inspired by the "hindsight heresy". Of course it does not follow that once these results are found they are then fallacious, but further independent data is required to test them.

The body of literature on economies of scale provides no help in ascertaining breakpoints eg J. E. Johnson, G. B. Flanagan and S. N. Weisbart (1980: 35) acknowledge their breakpoints were selected arbitrarily since "there have been no studies on firm structure and size which would have guided the choices made".

Using a more pragmatic approach inspection of the scatter of expenses by premiums did not indicate any obvious structural breaks. This is substantiated by the results so far produced.

\section{Model constrained to pass through the origin}

Returning to Table 1 it can be seen that none of the $B_{0}$ 's are statistically significant it is felt legitimate to fit the regression eliminating the constant term ie finding the best line to fit the data which passes through the origin. This eliminates the "scaling" factor and thereby makes the results easier to interpret. 


\section{Table 7}

$\begin{array}{lll}1980 & \mathrm{Y}=.918 \mathrm{X}+\mathrm{c} & \text { S. E. } \\ 1981 & \mathrm{Y}=.903 \\ 1982 & \mathrm{Y}=.918 \mathrm{X}+\mathrm{c} & .003 \\ 1983 & \mathrm{Y}=.922 \mathrm{C}+\mathrm{e} & .003 \\ 1984 & \mathrm{Y}=.902 \\ 1985 & \mathrm{Y}=.918 \mathrm{X}+\mathrm{e} & .002 \\ 1986 & \mathrm{Y}=.916 \mathrm{e}+\mathrm{e} & .002 \\ \end{array}$

The fact that the coefficient of $X$ is less than one throughout in Table 7 indicates that economies of scale may exist and that if so the degree to which they exist has been fairly stable over the period $1980 / 86$.

To say economies of scale exist it is necessary to test that the line fitted is appropriate for all sections of the data as it was pointed out in section 3 that the transformation used is really only appropriate for short sections of a curve. In section 5 such testing was done and it was concluded that the transformation is appropriate for all stretches.

\section{Conclusion}

It would appear at this stage reasonable to assume that the log-log transformation was not unnecessarily restrictive. In that case one can conclude that economies of scale exist for the life industry and the rate of proportionate increase of expenses against the proportionate increase of premiums is about $92 \%$ which has been constant during the period 1980-86. This is of a similar order to the result produced in (Praetz, 1983) where a 10\% increase in premiums was shown to produce an $8.9 \%$ increase in total costs. 


\section{BIBLIOGRAPHY}

ADELMAN, S. (1980). Optimal Operating Volumes on Economies of Scale in the Independent Insurance Agency: A cross-sectional study. Ph. D. thesis: University of Georgia.

BLUNDEN, W. E. (1986). Financial Aspects of Lifc Busincss. (London: CII Tuition Scrvice Study Course).

COLENUTT, D. W. (1977a). Determinants of expense ratios of United Kingdom life assurers. Journal of Risk and Insurance 44: 77-85.

COLENUTT, D. W. (1977b). Economies of scale in the United Kingdom ordinary life insurance. Journal of Applied Economics 9: 219-255.

CUMMINS, S. D. (1977). Economies of Scale in the Independent Insurance Agencies. Journal of Risk and Insurance 44 (4): $539-553$.

DOHERTY, N. A. (1981). The Measurement of Output and Economies of Scale in Property-Liability Insurance. Journal of Risk and Insurance 48: 390-402.

DUTTA, M. (1975). Econometric Methods. (Ohio: South-Western).

GEEHAN, R. R. and HIRSHHORN, R. (1977). Measuring the Real Output of the Life Insurance Industry. The Review of Economics and Statistics 59: 211-219.

GEEHAN, R. R. (1977a). The production of Financial and Insurance Services. Ph. D. thesis. Massachusetts Institute of Technology, USA.

GEEHAN, R. R. (1977b). Return to Scale in the Life Insurance Industry. Bell Journal of Economics 8: $497-513$

GEEHAN, R. R. (1986). Economies of Scale in Insurance: Implication for Regulation. Chapter 8 in: The Insurance Industry in Economic Development, ed. by B. Warow and R. B. Hill. (New York: University Press).

HOUSTON, D. C. and SIMON, R. M. (1970). Economies of Scale in Financial Institutions: A Study in Life Insurance. Econometrica 38: 856-864.

JOHNSON, J. E., FLANNAGAN, G. B. and WEISBART, S. N. (1980). Returns to Scale in the Property and Liability Insurance Market. Journal of Risk and Insurance 47: 19-45.

JOHNSTON, J. (1969). Statistical Cost Analysis. (New York: McGraw-Hill).

LIVESEY, F. (1983). Economics for Business Decisions. (London: Arrowsmith).

O'BRIEN, C. (1989). Measuring the Output of Life Assurancc Companies, Staple Inn Society. 5. 12.89 , publication forthcoming.

PEDOE, A. (1952). The Trend of Life Insurance Company Expenses. Transactions of the Society of Actuaries 4: $485-510$.

PEDOE, A. (1961). Further notes on the Trend of Life Insurance Company Expenses. Transactions of the Society of Actuaries 13: 1-19.

PRAETZ, P. D. (1983). The effect of size and other economic factors on the expense rate behaviour of UK Life Insurance Companies. Journal of the Institute of Actuaries 119 (2): 383-388. (Oxford: Alden Press).

RANSON, R. H. and HEADDON, C. P. (1989). With Profits without Mystery. Journal of the Institute of Actuaries. Publication forthcoming. (Oxford: Alden Prcss).

TAPP, J. (1986). Regulation of the UK Insurance Industry, Chapter 2 In: The Economics of Insurance Regulation, ed. by Fisinger, J. and Pauly, M. V. (London: Macmillan). 